\title{
Information literacy for first-year students: an embedded curriculum approach
}

\author{
T. ANDREWS* and R. PATIL \\ University of Western Sydney, Australia
}

(Received 23 January 2007; in final form 8 February 2007)

\begin{abstract}
The ability to access, evaluate and synthesise high-quality research material is the backbone of critical thinking in academic and professional contexts for Engineers and Industrial Designers. This is the premise upon which teaching and library staff developed Information Literacy (IL) components in Engineering \& Industrial Design Practice-a first-year unit of study in the School of Engineering at the University of Western Sydney. This paper documents the IL teaching and learning experience and evaluates and reflects upon how effective it was at helping students navigate their first tertiary level research tasks. It concludes that library sessions and assessment tasks were effective in introducing IL skills in concurrent development of critical thinking, based on feedback from library sessions, an online IL test, and assessment results.
\end{abstract}

Keywords: Information literacy; First-year students; Engineering \& Industrial Design

\section{Introduction}

Engineering and Industrial Design Practice (EIDP) is a first-year first semester unit for engineering and industrial design students offered by the School of Engineering at the University of Western Sydney (UWS). The unit introduces students to professional practice and develops communication, teamwork and problem-solving skills. The aim is to introduce these professions within global and local contexts and to encourage participants to develop their own personal ethos for practice, study and lifelong learning. At the conclusion of the unit, students are able to:

- contextualise the cultural significance of their profession;

- demonstrate problem-solving skills;

- establish information literacy, critical thinking and research skills;

- use computing tools to present work at a professional level;

- demonstrate written and oral communication skills;

\footnotetext{
*Corresponding author. Tara Andrews, Lecturer, School of Engineering, University of Western Sydney, Locked bag 1797, Penrith South DC NSW 1797, Australia. Phone: +61 29852 5073, Fax: +61 298525741. Email: t.andrews@uws.edu.au
} 
- successfully work in teams with peers, implementing teamwork, time and project management concepts; and

- understand concepts of: lifelong learning, professional responsibility, ethics, sustainability, and social responsibility.

The content delivered to support these outcomes comes via weekly lectures, tutorials and computer lab sessions wherein ideas and skills are introduced and case studies from industry are presented. Project work is conducted individually and in teams: a team research project is carried out throughout the semester towards which cumulative assessment tasks contribute. Students attend classes for up to $5 \mathrm{~h}$ per week over a 14-week teaching period and are expected to match this face-to-face time with independent and team study time.

\section{Information literacy and graduate attributes}

The teaching aims of EIDP reflect the University's commitment to ensuring that "UWS students learn to learn and graduate with the capacity to participate actively and responsibly in a diverse and changing world" (UWS 2004). A UWS graduate "commands multiple skills and literacies to enable adaptable lifelong learning", "and accesses evaluates and uses relevant information to solve problems and continue learning" (information literacy) (UWS 2003). A UWS Graduate also "applies knowledge through intellectual inquiry in professional or applied contexts", and "applies critical, reflective and creative skills to make informed decisions in professional or applied contexts" (applied critical thinking). The university clearly acknowledges the importance of information literacy in critical thinking, in the development of life-long learning skills, and for informed and responsible professional practice.

In keeping with the university's graduate attributes, teaching in EIDP seeks to develop the skills and understanding required to enable students to "know when they need information, and are then able to identify, locate, evaluate, organise, and effectively use the information to address and help resolve personal, job related, or broader social issues and problems" (ANZIIL 2004).

An information-literate person is able to:

1. recognise a need for information and determine the extent of information needed;

2. access the needed information effectively and efficiently;

3. critically evaluate information and the information seeking process;

4. manage information collected or generated;

5. apply prior and new information to construct new concepts or create new understandings;

6. understand economic, legal, social, ethical and cultural issues in the use of information; and

7. recognise information literacy as a prerequisite for lifelong learning (CAUL 2001).

Information literacy is becoming an increasingly important aspect of professional life for engineers and industrial designers and has been discussed in a range of recent articles (MacAlpine 2005). Industry demands skills beyond the technical or the generic: graduates are expected to define, engage with, and solve complex problems creatively, collaboratively and responsibly in rapidly changing global and local contexts. They must also deal with changes in information and communication technologies, types of information available and media, brought on by the information age and the revolutionary changes accompanying the internet's mass uptake.

Equipping engineering professionals with lifelong learning capabilities is necessary in changing industry contexts requiring professionals to reinvent themselves regularly to remain 
competitive in a globalised, lean workforce. Such changes in the professional contexts for engineers and industrial designers have been reflected in changing curricula directions led by the Higher Education Sector \& Industry bodies. Accreditation bodies like Engineers Australia and the Accreditation Board for Engineering and Technology (USA) have given substantial importance to lifelong learning competencies. Information literacy has also been identified in the Federal Government report, Higher education at the crossroads (2001), as part of "emerging skills and knowledge required by graduates for participation in democratic society". It is a prerequisite for participative citizenship, social inclusion, creation of new knowledge, personal empowerment and learning for life (ALIA 2001).

\section{Teaching approach}

Within the unit, information literacy is treated as the backbone to the development of critical thinking, lifelong learning and participative and responsible citizenship (Lupton 2004). Information literacy is much more than technological competence or on-line research. It supports critical thinking and reflection in the context of the increasingly extensive amounts of information now available through a wide range of technologies. As such, library skills are not treated as a stand alone tool box, but an integral part of the research and study process.

EIDP is therefore necessarily collaborative in its teaching approach, comprising library staff, the Learning Skills Unit and academics from the School of Engineering. Library staff and the learning skills unit are key to the development of the unit content, its delivery and the development and provision of study and research resources. Library staff deliver information literacy sessions, introducing students to the catalogue and research database resources, and provide ongoing assistance to students as they complete their assessment tasks. The Learning Skills Unit provides critical thinking, communication and teamwork content (with a resource book, online critical thinking module and a lecture). Engineering and industrial design academics run the tutorials and professional practice, problem solving, project management and teamwork content.

Collaboration between the School of Engineering and library staff is well established with demonstrated benefits to students in a range of units throughout their programs of study. Annual Course Experience Questionnaires (UWS 2006) consistently rate the services provided by the library very highly, which reflects the maintenance of strong links between academics and liaison librarians (as recorded in table 1).

The key teaching challenge is to shift the students' orientation away from searching for and presenting information categorically, and move toward critical argument construction supported by reputable evidence (the research communication should reflect a gradual process of understanding, that critically engages with a research question). Before EIDP, students have been used to searching Google ${ }^{\mathrm{TM}}$ for information categorically, and so excel at finding current and broad information suitable in the early stages of the research process. The shift in mode

Table 1. Rating of Library services by graduating students from the School of Engineering, UWS (UWS 2006).

\begin{tabular}{lcccccc}
\hline & $\begin{array}{c}\text { School of } \\
\text { Engineering } \\
\text { average } \\
(2005-2006)\end{array}$ & $\begin{array}{c}\text { Bachelor of } \\
\text { Design \& Technology } \\
\text { (course average) }\end{array}$ & $\begin{array}{c}\text { Bachelor of } \\
\text { Engineering } \\
\text { (average) }\end{array}$ & $\begin{array}{c}\text { Bachelor of } \\
\text { Industrial Design }\end{array}$ \\
\hline $\begin{array}{l}\text { Library services were } \\
\text { readily accessible }\end{array}$ & 82.65 & $\begin{array}{c}2005 \\
(100)\end{array}$ & $\begin{array}{c}2006 \\
(90)\end{array}$ & $\begin{array}{c}2005 \\
(73.5)\end{array}$ & $\begin{array}{c}2006 \\
(65.5)\end{array}$ & $\begin{array}{c}2005 \\
(76.9)\end{array}$ \\
\hline
\end{tabular}


required for a move to critical thinking needs to be supported by a change in the type of information being sourced: information needs to be treated as evidence, and Google ${ }^{\mathrm{TM}}$ will not be as effective as journal databases in providing them with reputable evidence sources to strengthen their own arguments. ${ }^{\dagger}$ It is only when critical argument construction is understood that students value information literacy, scholarly sources and a careful research process.

\subsection{Assessment tasks}

The assessment tasks for the unit are designed to encourage the application of IL skills within a challenging research task undertaken in teams. Teams of 4 or 5 students choose a research question based on a current topic of significant complexity, for example, food security, water shortage, population growth, and fuel sources. At the end of the teaching period, teams submit a research report and also verbally present their findings with slides.

An analysis of the task and topic was carried out in class in the second week of semester to assist students in constructing a team plan for the project's management. The first library session is delivered in the same week so that students had something to search for when introduced to the library catalogue system.

The first IL task was a 500 word annotation due in Week 6, requiring students to locate a relevant and credible journal article which they summarised and evaluated according to its relevance to their research topic and its bias, strengths or shortcomings. This submission followed the second library session which introduced the library journal databases and assists them in finding their source within class. They produced another annotation on a different source in Week 10 and assembled a list of 10 credible references in Week 7. These individual tasks were designed to demonstrate library skills and introduce critical thinking whilst furthering the teams' research progress: students must choose different sources to the rest of their team to ensure a breadth of research in the team research project.

Table 2 provides the results for 53 students in the annotation tasks in 2006. Although students often based their annotations on relevant and credible sources, they struggled to explicitly articulate their understanding of these concepts in relation to their sources. There were, however, a number of students who had difficulty distinguishing between general and scholarly sources and at which stage in the research process different types of sources used. This issue arose frequently throughout the semester and was demonstrated in the sources being annotated (annotations on general sources required resubmission) and in regular WebCT ${ }^{\mathrm{TM}}$ quizzes asking students to distinguish between source types and when it was appropriate to use them. The results improved in the second submission after reiteration of the concepts in class and in feedback provided from the first.

The final team research document was 4000-5000 words in length and included a problem statement, position statement, analyses of existing and proposed solutions to the problem, and their own solutions. A reflective e-journal was also kept throughout the semester. The position statement that students presented had to reflect an understanding of concepts of social responsibility and environmental sustainability and was the measuring stick for analyses of existing solutions and their own solutions.

Assessment for the team project in 2006 was individually and team-assessed. Students were assessed individually on their analysis of existing solutions to the problem within

\footnotetext{
${ }^{\dagger}$ This conceptualisation is informed by Booth et al. (1995) which, although humanities-oriented, is considered appropriate to the technical fields of Engineering and Industrial Design because that which is engineered or designed, the solution, stands as an argument as the result of a research process. Whatever the solution to a problem may be, it must be informed by a critical research process.
} 
Table 2. Annotation assessment results. ${ }^{\dagger}$

\begin{tabular}{|c|c|c|c|}
\hline Assessment criteria & Out of & $\begin{array}{l}\text { First } \\
\text { annotation } \\
\text { Week } 6\end{array}$ & $\begin{array}{l}\text { Second } \\
\text { annotation } \\
\text { Week } 10\end{array}$ \\
\hline $\begin{array}{l}\text { Provides full details of the text being annotated, and is referenced } \\
\text { correctly in Harvard style }\end{array}$ & 10 & 79 & 81 \\
\hline $\begin{array}{l}\text { Provides a summary of the key ideas/main points of the text, } \\
\text { with correct in-text referencing }\end{array}$ & 20 & 67 & 63 \\
\hline $\begin{array}{l}\text { Identifies the relevance of the text to the team project, and } \\
\text { answers the question how this article relates to the problem } \\
\text { team is solving }\end{array}$ & 20 & 54 & 58 \\
\hline $\begin{array}{l}\text { Includes discussion of the bias, strengths and/or shortcomings } \\
\text { of the text. Also clearly explains why source is credible }\end{array}$ & 10 & 50 & 66 \\
\hline Is clearly structured, with an introduction, body and conclusion & 20 & 68 & 69 \\
\hline \multirow{2}{*}{$\begin{array}{l}\text { Is written in a clear academic writing style, with correct spelling } \\
\text { and grammar }\end{array}$} & 20 & 63 & 68 \\
\hline & 100 & 63 & 67 \\
\hline
\end{tabular}

${ }^{\dagger}$ Sample 53 students selected on common band average markers.

Table 3. Research document assessment results. ${ }^{\dagger}$

\begin{tabular}{lc}
\hline Team assessment & $\%$ \\
\hline $\begin{array}{l}\text { Communication: structure, layout, English expression, referencing, use of images, } \\
\quad \text { editing (how well the ideas expressed individually come together as a whole) }\end{array}$ & 58 \\
Analysis and critical thinking: demonstrated understanding of the problem; strength of & 63 \\
$\quad$ argument for position/approach taken; problem logic and rationale & \\
Synthesis of research/problem-solving: how well solutions respond to the problem. & 56 \\
$\quad$ Degree to which solutions synthesise position taken and research findings; feasibility & \\
Individual assessment & 62 \\
English expression & 58 \\
Logic, strength and depth of argument & 60 \\
Total average & \\
\hline
\end{tabular}

${ }^{\dagger}$ Sample 45 students selected on common band average markers.

the team's wider argument. A breakdown of assessment is provided in table 3 (criteria are equally weighted).

Interestingly, students' critical thinking and analysis was well demonstrated within the team document but synthesising the research to envisage solutions was challenging. Students were able to draw on their research sources to support their own positions and to demonstrate a good depth of understanding of the nature of the problem. The application of IL to creative problem solving was perhaps too ambitious in this context. Not surprisingly, students encountered difficulty in maintaining a strong argument in a task demanding a multidimensional and collaborative approach.

\subsection{Library sessions}

To achieve the set outcomes of the subject and to train the students in research skills the library provided training in 19 batches. Based on the UWS library IL framework for first year, the information skills sessions took place in two parts, delivered during computer laboratories.

The first part focused on searching the online library catalogue effectively to locate appropriate books for their assessment topic, with a brief introduction to the services and facilities available on the library web page. The students were also introduced to the online books available through the library. The librarians encouraged a participative environment and students 
Table 4. Library test results after first library session. ${ }^{\dagger}$

\begin{tabular}{lc}
\hline Questions related to: & Average results in \% \\
\hline Type of citation & 68 \\
Identification of keywords in a topic & 69 \\
Boolean logic & 76 \\
Identify relevant databases & 95 \\
\hline
\end{tabular}

${ }^{\dagger}$ Sample 257 students.

were asked questions during the sessions to keep the training interesting and interactive. Print and online reference tools were also introduced as a means for students to gain a preliminary understanding of their topics. A class exercise was set for students to complete using the catalogue. This exercise was to build skills in searching material in the library by first identifying the type of material and then finding information with the help of the catalogue. A number of self-test questions were also made available to the students on $\mathrm{WebCT}^{\mathrm{TM}}$ so that they could follow up on points in their own time.

The second session showed students how to conduct library research and how to construct a search query using search techniques. Use of Google ${ }^{\mathrm{TM}}$ and Google Scholar ${ }^{\mathrm{TM}}$ was also discussed and demonstrated using an example. This same example was taken further demonstrating the search in library databases. As the students were required to produce a group report, they were asked to form groups and construct search queries and retrieve information on their topic. Each student had to note the search process and references on a sheet which was provided to them. The evaluation of information was also dealt with and students were given a handout for the different criteria against which to evaluate the information, including websites.

To assess the effectiveness of the library sessions, a library session evaluation survey was conducted through WebCT ${ }^{\mathrm{TM}}$. Participants were tested on their knowledge gained from the sessions (including their understanding of Boolean logic, their ability to identify different citation types, use of keywords and relevant databases (as seen in table 4)), and were asked to evaluate the usefulness of the sessions. The test showed that the outcomes of the session were achieved, as students achieved above $68 \%$ for each of the knowledge questions. The comments provided by students indicated that most had gained information they considered useful to their studies.

\section{Conclusion}

The assessment results and feedback from the library sessions suggest that EIDP is effective in introducing IL to first-year students. This we believe is due to the collaboration between library and teaching staff and the integration of IL within assessment tasks. What is most encouraging is that students in 2006 were able to demonstrate critical thinking and that this was developed concurrently with IL.

\section{Future directions}

There are a number of measures being taken in the next delivery of EIDP to improve the IL content in the unit, especially to assist students in identifying relevant and credible sources early in the research process. Students will be provided with a topic starter kit including a 
number of scholarly journal articles to base their first annotations on in order that they are provided with tangible examples of the kind of information that is available to them and the quality required at university level. To reinforce this, library sessions will focus more on evaluation of sources, with in class tasks to complete to ensure a thorough understanding of the importance of credibility of research sources. More time for this will be available as new students from 2007 will need to have successfully completed a web based introductory library tutorial as part of their orientation process.

\section{References}

Higher Education at the Crossroads: A Review of Australian Higher Education 2001. Available online at: http://www.dest.gov.au/crossroads (accessed November 2006).

Australian and New Zealand Information Literacy (ANZIIL), Australian and New Zealand Information Literacy Framework: Principles, Standards and Practice, 2nd edn, 2004. Available online at: http://www.anziil. org/resources/Info\%20lit\%202nd\%20edition.pdf (accessed November 2006).

Australian Library and Information Association (ALIA), Statement on information literacy for all Australians, 2001. Available online at: http://www.alia.org.au/policies/information.literacy.html (accessed November 2006).

Booth, W. et al., 1995 The Craft of Research (University of Chicago Press, Chicago).

Council of Australian University Librarians (CAUL), Information Literacy Standards, 2001. Available online at: http://www.caul.edu.au/caul-doc/InfoLitStandards2001.doc (accessed November 2006).

Lupton, M, The Learning Connection: Information Literacy and the Student Experience, 2004 (Auslib Press: Adelaide).

MacAlpine, B., Engineering + Information Literacy= One Grand Design. Proceedings of the 2005 American Society for Engineering Education Annual Conference \& Exposition, 2005 (American Society for Engineering Education).

University of Western Sydney, Academic Senate, The UWS graduate attributes, 2003 (UWS).

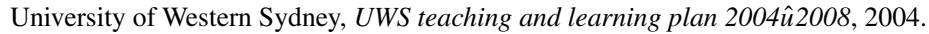

UWS College of Health \& Science, UWS Undergraduate Course Report, 2006 (UWS Planning \& Quality Division of Corporate Services).

\section{About the authors}

Tara Andrews is a lecturer in Industrial Design in the School of Engineering, University of Western Sydney, Australia. She has developed and delivered a wide range of subjects on research methods for designers, environmentally sustainable design and has supervised graduating students' self-directed industrial design projects. She is heavily engaged in curriculum development for industrial design and has managed a number of industry and community based student learning projects. Her main research interests include sustainable design theory, participatory design for accessibility in public spaces and sustainable futures.

Rohini Patil is a Liaison Librarian for the School of Engineering, University of Western Sydney, Australia. She has done her BSc and MLISc from India. She has extensive experience in library services and her areas of interest are information literacy and innovative services to the present generation clients. 